\title{
PERBAIKAN IRIGASI DAN KEHIDUPAN PETANI (STUDI KASUS IRIGASI DAN PERUBAHAN SOSIAL EKONOMI DI DESA BUGO, JEPARA)

\author{
Oleh : Yuli Priyana
}

\begin{abstract}
$\overline{\text { ABSTRACT }}$
This research aim to investigate the condition of the irrigation and the impact of the irrigation repair to the social change of the society in Bugo Village, especially to the landowner, cultivation system, farm income, absorption of labor, and the work relation in agrigulture. The approach that was used in this research is quality approach.

This research result was most of the farmer in Bugo still used traditional agriculture system. They unwilling to use the new technology. The impact to the society is the cange of cultivation system, that is from rice - secondary crop - secondary crop to rice - rice secondary crop. This changing has positive impact to farm income indirectly. There is 142 farmer in Bugo village. $38,7 \%$ of them were poor farmers, The managed haven't shown commercialism, but there was tendency apart of them harvested their rice to "pengedos" and the others to their neighbour.
\end{abstract}

\section{INTISARI}

Penelitian ini bertujuan untuk mengetabui kondisi irigasi serta pengarub perbaikan irigasi terbadap perubahan sosial masyarakat desa Bugo, terutama terbadap penguasaan laban, pola tanam, pendapatan, dan penyerapan tenaga kerja serta bubungan kerja pada bidang pertanian, Pendekatan yang dipergunakan adalab pendekatan kualitatif, dengan pendekatan ini dibarapkan akan mendapatkan informasi yang diharapkan, guna menunjang pembahasan penulis berusaba mendapatkan data kuantitatif yang relefan.

Dari hasil penelitian ini diketabui babwa petani pada desa Bugo masib banyakyang merupakan petani tradisional, artinya mereka masib enggan untuk menerima teknologi yang baru, lebib suka pada cara-cara yang biasa dilakukan oleb pendabulunya. Pada perbaikan irigasi menegemen dan saluran sekunder masib kurang sempurna sehingga air kurang biasa merata penyebarannya pada daerah oncoran. Pegarub yang timbul pada masyarakat yakni; terjadinya perubahan pola tanam dari padi-polowijo-polowijo menjadi padi-padi-polowijo, dari perubahan tersebut secara tidak langsung juga berpengarub positif terbadap pendapatan rumah tangga petani. Dengan petani-petani tiap bektarnya bertambah, ternyata tidak terjadi polarisasi penguasaan lahan pada petani kaya, dari 142 petani didapatkan $38,7 \%$ dari jumlab tersebut petani miskin menguasai $17,2 \%$ luas laban. Hubungan kerja pada petani juga belum nampak adanya komersialisme, hanya saja ada kecenderungan sebagian dari mereka memanenkan hasil panenannya kepada "pengedos", dan sebagian besar masib dipanenkan pada tetangga dengan sistem "derep". Tanaman padi ternyata banyak menyerap tenaga kerja dari pada tanaman polowijo pada daerab tersebut. Usaha sektor non pertanian pada daerah tersebut yang berkembang adalab 
usaha industri rumab tangga pangan, pada usaba ini ternyata juga cukup penyerap tenaga kerja dan memberikan penghasilan pada penduduk yang cukup lumayan.

\section{PENDAHULUAN}

Setelah ditemukannya beberapa jenis padi unggul pada tahun 1960-an diperkirakan bahwa swasembada beras dapat dicapai dengan waktu yang sangat singkat. Penemuan tersebut dianggap sebagai "revolusi hijau" (green revolution) yang mengacu pada intensifikasi pertanian pangan yaitu penggunaan varietas unggul. Sering dengan penemuan tersebut, muncul permasalahan daya dukung unsur lain yang dapat menghambat revolusi hijau. Salah satu unsur pendukung yang terpenting adalah tersedianya air irigasi yang cukup. Revolusi hijau tidak akan berhasil tanpa dukungan "revolusi biru" (blue revolution) (Asnawi, 1986).

Irigasi secara umum dipahami sebagai pengaturan dan pemakaian air pada tanah dengan maksud untuk kepentingan pertumbuhan tanaman, namun pengertian tersebut secara lebih luas merupakan suatu usaha untuk mendatangkan air ke sawah atau ladang dengan cara teratur dan kemudian membuangnya setelah tidak diperlukan lagi (Gandakoesoemah, 1975, Esraelson, 1962).

Bukti peninnggalan sejarah tentang irigasi di Jawa dimulai pada jaman Raja Purnawarman (abad V), yaitu dengan mengatur air sungai Cakung di Jawa-Barat untuk mengairi lahan pertanian. Jawa-Tengah dan Jawa Timur pada jaman itu juga ditemukan adanya bekas bendungan, selokan serta terowongan air, hanya saja pada waktu itu bendungan (Dawuhan) dibuat dari material yang sederhana seperti bambu, batu kali serta kayu atau papan (Van Der Meer, 1979)
Irigasi dapat meningkatkan produktivitas tanaman pangan terutama padi, dengan irigasi yang baik produktivitas pertanian per hektarnya menjadi lebih tinggi sehingga lebih banyak memberikan penghasilan kepada petani, disamping meningkatkan penyerapan tenaga kerja pada bidang pertanian. Perubahan tersebut memungkinkan timbulnya perubahan sosial masyarakat desa seperti sistem upah dan hubungan kerja. Irigasi yang baik tidak hanya dilihat dari kondisi fisik irigasi saja, namun sistem pengaturan air juga perlu diperhatikan, sehingga pemerataan pemakaian air irigasi dapat terwujud.

Penelitian ini dilakukan di desa Bugo, kecamatan Welahan, Kabupaten Jepara. Desa tersebut menarik untuk diteliti dikarenakan terdapat perbaikan sistem irigasi dari irigasi sederhana menjadi irigasi setengah teknis. Kenyataannya menunjukkan bahwa air yang masuk DAM kemudian menuju saluran primer dapat diatur karena adanya pintu air, demikian uga pada pintu masuk saluran sekunder. Keberadaan DAM memberikan dampak positif karena sebelumnya adanya DAM, jika musim hujan air melimpah dan menggenangi tanaman, sebaliknya pada musim kemarau air sungai tidak dapat dimanfaatkan untuk irigasi sawah.

Penelitian ini berusaha untuk mengetahui kondisi daerah penelitian sebelum dan sesudah adanya irigasi. Disamping itu peneliti ingin mengetahui keberadaan industri rumah tangga pangan yang ada di desa tersebut, dalam membantu meningkatkan perekonomian masyarakat desa.

Tujuan pokok dari penelitian ini adalah ingin mengetahui apakah 
dengan adanya perbaikan irigasi tersebut atau revolusi biru berpengaruh terhadap konsentrasi penguasaan lahan, pola tanam, pendapata, hubungan kerja serta penyerapan tenaga kerja pertanian. Selain itu juga ingin mengetahui kondisi perkembangan irigasi serta keberadaan sektor industri rumah tangga pangan dalam menunjang perekonomian masyarakat.

\section{METODE PENEIITIAN}

Desa Bugo dipilih secara purposive sebagai desa penelitian dengan pertimbangan bahwa desa tersebut mengalami perubahan sistem irigasi dari irigasi sederhana menjadi irigasi setengah teknis. Pendekatan yang dipakai penelitian ini adalah pendekatan kualitatif dengan melakukan wawancara bebas ataupun tersetruktur. Namun penulis juga memperhatikan data kuantitatif untuk menunjang hasil yang diinginkan penelitian ini, yaitu deskriptip eksploratif.

Responden dipilih orang yang mengetahui kondisi sosial ekonomi masyarakat desa tersebut pada sebelum dan sesudah adanya perbaikanirigasi. Hal ini tidak sulit karena perbaikan irigasi terjadi setelah tahun 1986. Mereka pada umumnya adalah petani penggarap dan seberapa key Informan seperti mantan Kepala Desa, mantri pengairan dan punggawa Desa Bugo.

Pada penelitian ini data yang dikumpulkan meliputi kondisi fisik desa, penduduk, perkembangan irigasi, kondisi irigasi serta implikasi perkembangan irigasi terhadap; pola pergiliran tanaman, pemilikan dan penguasaan lahan, pendapat dan hubungan kerja serta ketenaga kerjaan.
Selain itu juga keberadaan industri rumah tangga pangan.

\section{PEMBAHASAN}

\section{Kondisi Irigasi}

Saluran irigasi yang terdapat pada daerah penelitian meliputi saluran primer dan sekunder yang terbuat dari tanah atau selokan, sehingga memungkinkan hilangya air lebih banyak oleh karena infiltrasi dan perkolasi. Pengelolaan irigasi pada daerah tersebut kurang baik, terlihat bahwa petani mengalirkan air ke sawah mereka tanpa memperhatikan giliran. Padahal wilayah oncoran DAM tersebut tidak hanya wilayah Desa Bugo saja, namun mencakup desa-desa di sekitarnya seperti; Sobokerto, Karanganyar dan Ujungpandan. Sehingga sawah yang letaknya di luar desa Bugo yang jauh dari pintu air akan semakin sedikit mendapatkan air.

\section{Pemilikan Dan Penguasaan Lahan}

Pemilikan lahan sawah oleh petani di desa Bugo berdasar leter $\mathrm{C}$ relatif sempit yakni rata-rata 0,238 hektar per pemilik. Pemilikan sawah ini dapat berasal dari membeli, warisan, hibah atau norowito (Bakon). Norowito sebelum menjadi lahan milik merupakan lahan milik komunal yang diberikan kepada setiap keluarga pada desa tersebut untuk dikerjakan dan tidak diberi hak untuk menjualnya. Tanah ini jika penggarapnya meninggal dapat diwariskan kepada nak laki-lakinya, jika tidak mempunyai anak laki-laki maka 
lahan garapan tersebut akan dicabut diberikan kepada orang lain yang disebut magang. Undang-undang pokok agraria tahun 1960, menyebutkan bahwa tanah tersebut diberikan kepada peggarap terakhir segagai hak milik (Sediono Tjondronegoro, 1984). Penyebaran pemilikan lahan dapat diliaht pada tabel 5.1

Tabel 2.1 Penyebaran pemilikan lahan sawah di desa Bugo tahunn 1991

\begin{tabular}{|c|c|c|}
\hline $\begin{array}{c}\text { Luas laha } \\
\text { (HA) }\end{array}$ & $\begin{array}{c}\text { Jumlah pe- } \\
\text { milik (KK) }\end{array}$ & Prosentase \\
\hline$>1$ & 5 & 2, \\
$0,50-0,99$ & 21 & 7,9 \\
$<0,49$ & 240 & 90,0 \\
\hline Jumlah & 266 & 100 \\
\hline
\end{tabular}

Sumber: Letter C

Penguasaan lahan sawah pada daerah penelitian relatif merata dan tidak terlihat adanya gejala polariasi penguasaan lahan. Menurut Triyanto Widodo (1990) penguasaan lahan dapat dikatakan timpang jika $40 \%$ penduduk (petani) bawah menguasai $<12 \%$ lahan yang ada. Pada daerah penelitian dari sejumlah 142 petani, yang $38,7 \%$ dari jumlah pemilik lahan $0,01-0,24 \mathrm{Ha}$ menguasai lahan seluas $17,2 \%$ dari luas lahan.

\section{Pola Pergiliran Tanaman}

Pengaruh dari perbaikan sistem irigasi adalah perubahan pola tanam serta meningkatnya produktivitas pertanian per hektarnya terutama padi hal ini karena semula waktu sistem irigasi masih irigasi sederhana pola tanam yang ada adalah padi-polowijopolowijo, kemudian setelah sistem irigasi menjadi lebih baik maka berubah menjadi padi-padi-polowijo. Perubahan tersebut menyebabkan produksi padi menjadi lebih meningkat, karena dalam setahun dapat ditanam padi dua kali.

\section{Pendapatan Petani dan Hubungan Kerja}

Pendapatan petani sampel pada daerah penelitian dapat digolongkan menjadi tiga yaitu petani kecil dengan pendapatan rumah tangga setahun Rp. 905.100,- petani menengah sedangkan petani besar mempunyai pendapatan rata-rata Rp. 1.225.300,dalam setahun.

Berdasarkan informasi yang saya peroleh dari informan, pendapatan petani pada daerah penelitian meningkat dikarnakan produktivitas lahan pertanian menjadi naik setiap hektarnya. Pendapatan pak Saripan sebelum adanya perbaikan irigasi selama satu tahun setara dengan $1.871,5$ $\mathrm{Kg}$ beras, setelah ada perbaikan irigasi meningkat menjadi $2.013,5 \mathrm{Kg}$ atau $7,5 \%$. Pendapatan buruh tani (laki-laki) dahulu Rp. 1300,- selama satu hari kerja (tujuh jam), sekarang menjadi Rp 2500,-Ongkos ngluku yang dahulunya satu hari kerja $\mathrm{Rp} 5.300$,- sekarang menjadi Rp. 8.500,-. Pekerjaan ngluku ini mulai nampak ada saingan karena sudah mulai ada beberapa petani yang meluku sawahnya dengan traktor, dengan alasan lebih cepat dan ongkosnya murah.

Petani pada waktu menuai padi terutama yang golongan tua lebih suka di panenkan kepada tetangganya walupun hasil yang diterima menjadi lebih kecil, mereka ingin membagi penghasilan kepada tetangganya. Ongkos panen ini adalah seperenam atau sepertujuh dari hasil panen tergantung dari jauh dekatnya sawah 
dengan rumah. Namun sekarang ini ada gejala petani pada waktu panen padi dengan cara di "Doskan" atau diborongkan kepada orang yang biasanya kepada orang luar desa. Upah "Dos" ini setiap kuintalnya sebesar Rp 3000,- dan ini hasilnya lebih banyak karena padi langsung dirontok di sawah degan perontok sederhana dan di bawah pulang langsung berujud "gabah", dengan demikian biasanya "gabah" yang tercecer lebih sedikit.

Sistem bagi hasil nampaknya hampir sama, sebelum ada irigasi baik berlaku maro dan mrotelu dan sampai berlaku hanya saja yang dahulunya itu ada "sromo" atau lamaran pada sistem maro sekarang sudah tidak berlaku. Maro ini biasanya pada waktu musim tanam pertama, yang punya sawah tidak tahu apa-apa pada waktu panen mendapakan bagian separuh dari hasil. Sedangkan mrotelu terjadi pada musim tanam kedua dan ketiga dengan catatan pemilik sawa memberikan bantuan untuk mengerjakan sawah dan pupuk, setelah panen mendapatkan bagian sepertiga dari hasil panen. Ongkos menyewa sawah juga mengalami kenaikan yang cukup drastis karena sebelum ada irigasi sewa tanah selama 1 tahun sebesar Rp 200.000,- sekarang menjadi Rp. 500.000,-.

\section{Tenaga Kerja}

Kebutuhan tenaga kerja dapat dilihat pada setiap jenis kegiatan pertanian dan pola tanamnya. Karena setiap jenis tanaman mempunyai daya serap tenaga kerja yang tidak sama. Misalnya tanaman padi akan membutuhkan tenaga yang jumlahnya tidak sama dengan jenis tanaman lain. Kebutuhan tenaga kerja pada tanaman padi setiap hektarnya per hari kerja adalah 245 orang terdiri dari 110 orang laki-laki dan 135 orang perempuan. Untuk jenis tanaman jagung memerlukan tenaga sebanyak 162 orang terdiri dari 117 orang laki-laki dan 45 orang perempuan. Untuk jenis tanaman ketela rambat memerlukan tenaga sejumlah 140 orang yang terdiri dari 100 orang tenaga laki-laki dan 40 orang perempuan. Untuk lebih jelasnya lihat tabel 5.1, 5.2, 5.3.

Tabel 5.1. Kebutuhan tenaga dalam satu Hektar (Ketela Rambat)

\begin{tabular}{|l|c|c|c|}
\hline \multirow{2}{*}{ Jenis pekerjaan } & \multicolumn{3}{|c|}{ Jumlah tenaga } \\
\cline { 2 - 4 } & laki2 & Pr & hewa \\
\hline Mengolah tanah (ngluku) & 3 & & 6 \\
Mencangkul (ganden) & 15 & & \\
membuat guluman & 15 & & \\
membuat sumur & 25 & & \\
Menyiram & $4 \times 5$ & 4 & \\
Menanam & 2 & 15 & \\
memupuk & $4 \times 2$ & & \\
Menyiram & $4 \times 3$ & & \\
Membaliki & & 25 & \\
Panen & 100 & 40 & 6 \\
\hline Jumlah & &
\end{tabular}

Sumber: Data Primer 
Tabel 5.2. Kebutuhan tenaga dalam satu hektar dalam satu hari kerja ( Jagung ).

\begin{tabular}{|l|l|c|c|}
\hline \multirow{2}{*}{ Jenis pekerjaan } & \multicolumn{3}{|c|}{ Jumlah tenaga } \\
\cline { 2 - 4 } & Laki-laki & perempuan & hewan \\
\hline Ngluku & 3 & & 6 \\
Mencangkul ( Mencacah) & 15 & & \\
Membuat sumur & 25 & & \\
Ngluang / tandur & 15 & 15 & \\
Memupuk & 2 & & \\
Mengairi & $4 * 5$ & & \\
Memberantas hama & 2 & 35 & \\
Menimbun tanaman & 35 & 30 & \\
Panen & 112 & 45 & 6. \\
\hline Jumlah & & & \\
\hline
\end{tabular}

Sumber : Data Primer

Tabel 5.3. Kebutuhan tenaga kerja pada tanaman padi .

\begin{tabular}{|c|c|c|c|}
\hline \multirow{2}{*}{ Jenis pekerjaan } & \multicolumn{3}{|c|}{ Jumlah tenaga } \\
\hline & Laki-laki & perempuan & hewan \\
\hline $\begin{array}{l}\text { 1. Membuat persemaian } \\
\text { Mencangkul } \\
\text { Meratakan } \\
\text { Menabur } \\
\text { Memupuk } \\
\text { Memberantas hama } \\
\text { 2. Pengolahan tanah } \\
\text { Babat jerami } \\
\text { Membajak } \\
\text { Meratakan nggaru } \\
\text { Tamping / mencangkul } \\
\text { 3. Menanam dan memelihara bibit } \\
\text { Mencabut bibit } \\
\text { Tanam } \\
\text { Memupuk } \\
\text { Menyiang I } \\
\text { Memberantas hama } \\
\text { Menyiang II } \\
\text { 4. Panen }\end{array}$ & $\begin{array}{l}16 \\
4 \\
4 \\
2 \\
2 \\
12 \\
2 \\
1 \\
20 \\
35 \\
6 \\
6\end{array}$ & $\begin{array}{l}50 \\
20 \\
15 \\
50\end{array}$ & $\begin{array}{l}4 \\
2\end{array}$ \\
\hline Jumlah & 110 & 135 & 6 \\
\hline
\end{tabular}

Sumber : Data Primer 


\section{Kesempatan kerja pada sektor non pertanian}

Rata-rata pemilikan lahan sawah pada daerah penelitian adalah 0,238 hektar per pemilik, sehingga dapat dikatakan bahwa pemilikan tersebut relatif sempit. Akibat dari sempitnya lahan pertanian tersebut maka penghasilan rumah tangga petani daerah tersebut menjadi rendah.

Sempitnya lahan pertanian dan sistem irigasi yang tidak baik akhirnya mendesak petani untuk mencari lapangan pekerjaan lain terutama pada sektor nonpertanian. Banyak ibu-ibu rumah tangga yang membantu keluarganya dengan jualan di pasar, demikian pula pada musim kemarau pergi ke kota untuk berjualan es atau dawet. Kemudian ada penduduk setempat yang memulai membuat usaha kue "moho", yaitu pak Sunar dan Kaswi (tahun 1955) yang kemudian diikuti oleh para tetangganya sampai sekarang. Hingga saat ini jumlah rumah tangga yang mengusahaka makanan kecil ada 35 orang yang usahanya besar hanya delapan orang, dengan jumlah tenaga 10-14 orang, yang lainnya tergolong kecil dengan tenaga kerja keluarga. Dengan adanya usaha membuat makanan kecil ini maka timbul pekerjaan "peloper", yakni orang-orang yang memasarkan produksi makanan tersebut. Jumlah tenaga kerja yang terlibat pada sektor makanan kecil ini sekitar 160, orang.

Setelah adanya perbaikan sistem irigasi yang mengakibatkan produktivitas padi meningkat, maka timbul pekerjaan yang dinamakan "nguyang", yaitu usaha membeli gabah pada penduduk kemudian diselepkan setelah jadi beras baru dijual. Usaha ini skala kecil karena terbatasnya alat angkut berupa sepeda.

Ternyata kesempatann kerja pada sektor non pertanian pada daerah ini cukup potensial dan sanngat membantu mengurangi pengangguran daerah tersebut.

\section{KESIMPULAN DAN SARAN}

Kondisi saluran irigasi yang masih terbuat dari tanah memungkinkan banyak jumlah air yang hilang oleh karena mengalami infiltrasi dan perkolasi. Selain itu pengaturan air yang kurang baik akan merugikan pemilik sawah di bagian hilir.

Perbaikan sistem irigasi pada desa tersebut menyebabkan perubahan pola tanam dari padi-polowijo-polowijo menjadi padi-padi-polowijo, sehingga mengakibatkan produktivitas padi meningkat. Dengan begitu maka pendapatan petani menjadi lebih besar menyebabkan angkanya yang konkrit, harga sewa tanah menjadi lebih mahal. Pola tanam yang berubah mengakibatkan perubahan penyerapan tenaga kerja, karena tanaman padi lebih banyak menyerap tenaga kerja dari pada tanaman lain yang ada pada daerah penelitian.

Hubungan kerja mulai ada kecenderungan mengalami perubahan, yakni dengan mulai masuknya pengedos, traktor dan upah buruh mulai dibayar semua dengan uang tanpa memberikan makan, yang oleh penduduk setempat disebut dengan "x lagis. 
Kesempatan kerja pada sektor non pertanian ternyata menyerap tenaga kerja yang banyak, selain memberikan penghasilan yang cukup.

Saran; Untuk lebih baiknya hendaknya pemerintah membantu membuat saluran tersier dan saluran primer dan sekunder yang ada masih terbuat dari tanah sehingga air tidak banyak yang hilang. Perbaikan saluran irigasi hendaknya dibuat dari semen agar lahan sawah pada desa yang jauh dari pintu air cukup mendapatkan air irigasi.

\section{DAFTAR PUSTAKA}

Ace Partaredja. 1980. Beberapa Masalah Dalam Produksi Bahan Makan. Prisma, nomer 9 September 1980.

Boot. A. E. 1989. Perkembangan Angkatan Kerja Pertanian di Jawa-Tengah dan luar Jawa. Prisma, Nomer 5 tahun 1989.

Effendi Pasandaran dan Coller. W.C. 1986. Irigasi Perencanaan dan Pengelolaan, Jakarta: Gramedia.

Esraelson. O.W. 1962. Irrigation Principles and Practies. New York: John Willy and sons. Inc.

Faisal Kasryno. 1984. Prospek Pembangunan Ekonomi Pedesaan Indonesia. Jakarta: Yayasan Obor.

Gandakoesoemah. 1975. Irigasi. Jakarta: Sumur Bandung.

Noeng Muhadjir. 1975. Methodologi Penelitian Kualitatif. Yogyakarta: Rake Sarasin.

Sediono MP Tjondronegoro dan Gunawan Wiradi. 1984. Dua Abad Penguasaan Tanab. Pola Penguasaan Tanah Pertanian di Jawa dari masa ke masa. Jakarta: PT. Gramedia.

Sudarjo Adiwikarto. 1984. Dampak Irigasi Jatiluhur terhadap Pola Kerja Keluarga Petani. Prisma, nommer 9 tahun 1984. LP3ES.

Syofyan Asnawi. Peranan Maslaah Irigasi Dalam mencapai Dan Melestarikan Swasembada Pangan. Prisma, nomer 2 tahun 1988, LP3ES.

Triyanto Widodo. 1990. Indikator Ekonomi Dalam Perbitungan Perekonomian di Indonesia. Yogyakarta: Kanisius.

Van Setten Van Der Meer. 1979. Sawab Cultivation in Ancient Java. Canberra: Austalian National University Press.

Werner Rall. 1983. Struktur Pemilikan Tanab di Indonesaia. Jakarta: CV. Rajawali. 